\section{Case Reports in Neurology}

Case Rep Neurol 2020;12:359-364

DOI: $10.1159 / 000509345$

Published online: October 9, 2020

(c) 2020 The Author(s)

Published by S. Karger AG, Basel

www.karger.com/crn

This article is licensed under the Creative Commons Attribution-NonCommercial 4.0 International License (CC BY-NC) (http://www.karger.com/Services/OpenAccessLicense). Usage and distribution for commercial purposes requires written permission.

\title{
Avoiding Anchoring Bias in the Times of the Pandemic!
}

\author{
Zohaib Yousaf $^{a} \quad$ Mohammed Yaseen Ahmed Siddiqui ${ }^{a}$ \\ Kamran Mushtaq ${ }^{b}$ Sayeda Efath Feroz ${ }^{a} \quad$ Mohamed Aboukamar ${ }^{C}$ \\ Mohamed Gaafer Hussein Mohamedali ${ }^{a} \quad$ Haseeb Chaudhary ${ }^{d}$ \\ aMedicine, Hamad Medical Corporation, Doha, Qatar; ${ }^{b}$ Gastroenterology and Hepatology, \\ Hamad Medical Corporation, Doha, Qatar; Infectious Disease, Hamad Medical \\ Corporation, Doha, Qatar; ${ }^{d}$ Medicine, Reading Hospital, Tower Health Medical group, \\ West Reading, PA, USA
}

\section{Keywords}

COVID-19 · SARS-CoV-2 · Meningoencephalitis · Tuberculosis · Tuberculoma

\begin{abstract}
COVID-19 has a broad spectrum of clinical presentations, including central nervous system manifestations that are not uncommon. The high pretest probability of COVID-19 in pandemic can lead to anchoring. We present a patient of COVID-19 pneumonia who presented with dyspnea and acute confusional state. His initial workup was suggestive of tuberculous meningoencephalitis with lymphocytic pleocytosis, high protein in CSF analysis, and suspicious MRI findings, which was later confirmed with a positive CSF culture. To the best of our knowledge, it is the first such case. Anchoring to the diagnosis of COVID-19 may deter clinicians from considering other concurrent diagnoses and a poor outcome consequently.




\section{Case Reports in Neurology}

\begin{tabular}{l|l} 
Case Rep Neurol 2020;12:359-364 \\
\hline DOI: 10.1159/000509345 & $\begin{array}{l}\text { @ 2020 The Author(s). Published by S. Karger AG, Basel } \\
\text { www.karger.com/crn }\end{array}$
\end{tabular}

Yousaf et al.: COVID-19 and Tuberculous Meningoencephalitis

\section{Introduction}

Anchoring is a cognitive bias whereby an individual depends too heavily on the initial piece of information when making decisions. In the current pandemic, many places have dedicated healthcare facilities for managing COVID-19 patients, which leads to a predisposition to anchoring bias. COVID-19 presents with a myriad of presentations that mainly include respiratory, cardiac, neurological, and gastrointestinal symptoms. Evidence continues to emerge, linking the role of COVID-19 to creating a prothrombotic and inflammatory state that causes numerous central nervous system (CNS) complications like a cerebrovascular accident, Guillain-Barré syndrome, acute transverse myelitis, and acute encephalitis [1]. Other reports of CNS infections have been limited to one case presenting with seizures, MRI changes, and positive RT-PCR for SARS-COV-2 in the CSF of the patient [2]. Another case report describes a COVID-19 patient with altered sensorium and psychiatric symptoms [3].

We present a case of confirmed COVID-19 pneumonia with concurrent neurological symptoms secondary to tuberculous meningoencephalitis.

\section{Case Report}

A 20-year-old Nepalese man, previously fit and well, presented with a 1-day history of abnormal behavior. He had a 1-week history of fever, cough, nausea, and vomiting. Upon initial presentation, he was febrile $\left(38.5^{\circ} \mathrm{C}\right)$ and tachypneic $(24 / \mathrm{min})$, but otherwise hemodynamically stable with normal oxygen saturation on ambient air. Neurological examination showed a GCS of 12/15 and nuchal rigidity with a positive Kernig and Brudzinski sign. The chest examination was remarkable for bilateral basal crackles. The initial basic lab workup was unrevealing (as shown in Table 1). A chest X-ray revealed increased bilateral bronchovascular markings, but no organized infiltrates. He received a meningeal dose of ceftriaxone and acyclovir based on local empiric treatment guidelines for meningoencephalitis. An urgent CT of the brain did not show any acute intracranial pathology or old granulomatous lesions. Lumbar puncture revealed lymphocytic pleocytosis with low glucose of $1.5 \mathrm{mmoL}$ and high protein of $1.95 \mathrm{~g} / \mathrm{L}$ (as shown in Table 2). AFB smear and tuberculosis PCR from CSF was negative. Quantiferon Gold for tuberculosis was indeterminate. HIV 1 and 2 serology tests were negative.

Due to the high index of suspicion for tuberculous meningitis based on CSF analysis, the patient was started on anti-tubercular treatment with isoniazid, rifampicin, ethambutol, and pyrazinamide along with dexamethasone. Subsequently, an MRI of the brain revealed multiple ring-enhancing lesions consistent with tuberculomas and leptomeningeal enhancement suggestive of granulomatous meningoencephalitis (Fig. 1). His nasopharyngeal swab was positive for COVID-19 RT-PCR, and he received treatment with hydroxychloroquine and azithromycin as per local guidelines with a normal QTc.

The patient started to improve clinically on the 5 th day of hospitalization. His tuberculosis culture from the CSF was positive on the 17th day of incubation. The patient's COVID-19 symptoms and tuberculous meningoencephalitis dramatically improved; therefore, the plan was to complete the total duration of anti-tuberculous drugs by tapering of steroids as per local guidelines. 


\section{Case Reports in Neurology}

\begin{tabular}{l|l} 
Case Rep Neurol 2020;12:359-364 \\
\hline DOI: 10.1159/000509345 & $\begin{array}{l}\text { ( ) 2020 The Author(s). Published by S. Karger AG, Basel } \\
\text { www.karger.com/crn }\end{array}$ \\
\hline
\end{tabular}

Yousaf et al.: COVID-19 and Tuberculous Meningoencephalitis

\section{Discussion}

COVID-19 is caused by the severe acute respiratory syndrome coronavirus 2 (SARS-COV2). Its clinical presentation commonly includes fever, cough, fatigue, anorexia, and myalgia [4]. Chemosensory dysfunction, e.g., anosmia and dysgeusia, have also been reported [5]. In addition to the respiratory system, gastrointestinal and cardiology involvement is also seen [6,7].

Neurological involvement in SARS-COV-2 is not uncommon. A retrospective analysis of 214 patients by Mao et al. [8] showed neurological involvement of up to $40 \%$, which was more common in severe cases, $14 \%$ had an impaired level of consciousness, and $5 \%$ of patients had an ischemic stroke. Another prospective case series of 53 patients from France revealed 8 patients that had leptomeningeal enhancement on imaging. The CSF analysis showed no cells with occasional oligoclonal bands and negative SARS-COV-2 RT-PCRs in all patients [9]. Although COVID-19 could explain our patient's clinical presentation, his lumbar puncture analysis was suspicious of tuberculous meningitis. Moreover, the brain MRI showed multiple ringenhancing lesions in the bilateral cerebellar hemispheres and frontonasal regions that were highly suggestive of tuberculomas along with diffuse leptomeningeal enhancement in the midbrain, bilateral cerebellar folia, anterior interhemispheric region, and bilateral frontal sulci more on the right side. Given the findings from CSF analysis and MRI of the brain, anti-tuberculous therapy with dexamethasone was initiated with a decision to see the response to treatment with subsequent imaging.

While pulmonary tuberculosis remains the more common presentation of infection with Mycobacterium tuberculosis, tuberculous meningitis constitutes about $1 \%$ of all cases [10]. The mortality in tuberculous meningitis remains exceptionally high. Clinical response to antitubercular treatment in all forms of CNS tuberculosis is contingent on an early diagnosis before irreversible neurological deficit occurs; therefore, the management strategy should involve an early diagnosis coupled with aggressive treatment $[11,12]$. The culture from the CSF analysis confirmed tuberculous infection 3 weeks later. Our patient improved significantly upon the initiation of anti-tubercular treatment with dexamethasone.

\section{Conclusion}

In the present pandemic, there is a temptation to link the clinical presentation of any COVID-19 patient to its multi-systemic involvement. The authors suggest eliminating the possibility of co-existing infections that may present similarly. Overcoming the anchoring bias can thus affect morbidity and mortality.

\section{Statement of Ethics}

The patient has given written informed consent to publish this case, including the publication of images. The institute's committee approved the manuscript on human research. We avoid information revealing the subject's identity. The study was conducted ethically in accordance with the World Medical Association Declaration of Helsinki. Approval from the institutional research body: The manuscript has completed the review process by the medical 


\section{Case Reports in Neurology}

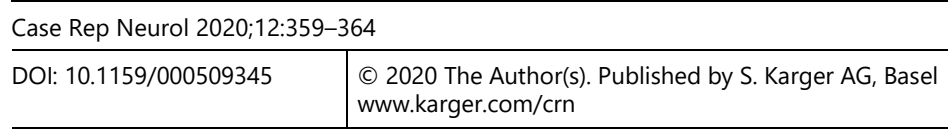

Yousaf et al.: COVID-19 and Tuberculous Meningoencephalitis

research council of Hamad Medical Corporation, using their online platform "www.abhath.hamad.qa". The ID assigned to the manuscript is MRC-04-20-295, and it has completed the process successfully (https://www.wma.net/policies-post/wma-declaration-of-helsinkiethical-principles-for-medical-research-involving-human-subjects/).

\section{Conflict of Interest Statement}

The authors certify that they have no conflict of interest and no affiliations with or involvement in any organization or entity with any financial or non-financial interest in the subject matter or materials discussed in the manuscript.

\section{Funding Sources}

Open Access funding was provided by the Qatar National Library.

\section{Authors Contributions}

Z.Y.: Case identification, literature review, manuscript writing. M.S.: Manuscript writing, informed consent, and literature review. M.M. and S.A.K.: Involved in the diagnosis and management of the patient. S.F.: Manuscript writing. K.M. reviewed the final manuscript. H.C.: Final manuscript review as senior author.

\section{References}

1 Ahmad I, Rathore FA. Neurological manifestations and complications of COVID-19: A literature review. J Clin Neurosci. 2020 Jul;77:8-12.

2 Moriguchi T, Harii N, Goto J, Harada D, Sugawara H, Takamino J, et al. A first case of meningitis/encephalitis associated with SARS-Coronavirus-2. Int J Infect Dis. 2020 May;94:55-8.

3 Yin R, Feng W, Wang T, Chen G, Wu T, Chen D, et al. Concomitant neurological symptoms observed in a patient diagnosed with coronavirus disease 2019. J Med Virol. 2020 Apr 15;10.1002/jmv.25888.

4 Wang D, Hu B, Hu C, Zhu F, Liu X, Zhang J, et al. Clinical Characteristics of 138 Hospitalized Patients With 2019 Novel Coronavirus-Infected Pneumonia in Wuhan, China. JAMA. 2020 Mar;323(11):1061-9.

5 Giacomelli A, Pezzati L, Conti F, Bernacchia D, Siano M, Oreni L, et al. Self-reported Olfactory and Taste Disorders in Patients With Severe Acute Respiratory Coronavirus 2 Infection: A Cross-sectional Study. Clin Infect Dis. 2020 Jul;71(15):889-90.

6 Zhang H, Liao YS, Gong J, Liu J, Xia X, Zhang H. Clinical characteristics of coronavirus disease (COVID-19) patients with gastrointestinal symptoms: A report of 164 cases. Dig Liver Dis. 2020 Oct;52(10):1076-9.

7 Chen T, Wu D, Chen H, Yan W, Yang D, Chen G, et al. Clinical characteristics of 113 deceased patients with coronavirus disease 2019: retrospective study. BMJ. 2020 Mar;368:m1091.

8 Mao L, Jin H, Wang M, Hu Y, Chen S, He Q, et al. Neurologic Manifestations of Hospitalized Patients With Coronavirus Disease 2019 in Wuhan, China. JAMA Neurol. 2020 Jun;77(6):683-90. 
9 Helms J, Kremer S, Merdji H, Clere-Jehl R, Schenck M, Kummerlen C, et al. Neurologic Features in Severe SARS-CoV-2 Infection. N Engl J Med. 2020 Jun;382(23):2268-70.

10 Scott C, Kirking H, Jeffries C, Price S, Pratt R. Tuberculosis Trends — United States, 2014. MMWR Morb Mortal Wkly Rep. 2015 Mar 20;64(10):265-9.

11 Thwaites G, Fisher M, Hemingway C, Scott G, Solomon T, Innes J; British Infection Society. British Infection Society guidelines for the diagnosis and treatment of tuberculosis of the central nervous system in adults and children. J Infect. 2009 Sep;59(3):167-87.

12 Indrajit IK, Ganesan S. Magnetic Resonance Imaging in Intracranial Tuberculosis. Med J Armed Forces India. 2001 Oct;57(4):292-7.

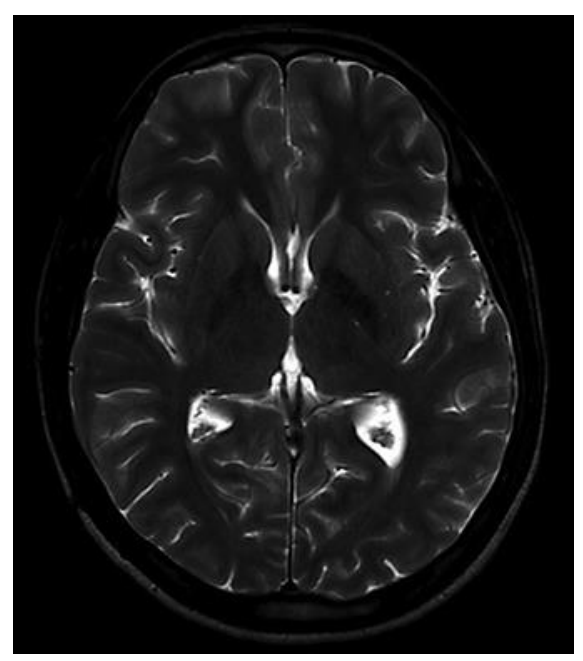

Fig. 1. MRI of the brain showing a tuberculoma and leptomeningeal enhancement. 
Case Reports in

Neurology
Case Rep Neurol 2020;12:359-364

\begin{tabular}{l|l}
\hline DOI: $10.1159 / 000509345$ & (c) 2020 The Author(s). Published by S. Karger AG, Basel
\end{tabular} www.karger.com/crn

Yousaf et al.: COVID-19 and Tuberculous Meningoencephalitis

Table 1. Investigations

\begin{tabular}{|c|c|}
\hline Investigation & Value \\
\hline White cells (per mm³) & 7.2 \\
\hline Neutrophils (per mm³) & 5.2 \\
\hline Lymphocytes (per mm³) & 0.8 \\
\hline Eosinophils (per mm³) & 0.0 \\
\hline Monocytes (per $\mathrm{mm}^{3}$ ) & 1.2 \\
\hline Platelet count (per mm³) & 222 \\
\hline Hemoglobin, g/L & 13.5 \\
\hline $\mathrm{CRP}, \mathrm{mg} / \mathrm{L}$ & $<5$ \\
\hline Total protein, g/L & 76 \\
\hline Albumin, g/L & 34 \\
\hline Alanine aminotransferase, unit/L & 27 \\
\hline Aspartate aminotransferase, unit/L & 31 \\
\hline Glucose, mmol/L & 7.8 \\
\hline Urea, mmol/L & 5 \\
\hline Creatinine, $\mu \mathrm{mol} / \mathrm{L}$ & 57 \\
\hline EGFR, $\mathrm{ml} / \mathrm{min} / 1.73 \mathrm{~m}^{2}$ & 141 \\
\hline Serum ferritin, $\mu \mathrm{g} / \mathrm{L}$ & 379 \\
\hline Bicarbonate, mmol/L & 22 \\
\hline Lactic acid, mmol/L & 2.4 \\
\hline TSH level, mIU/L & 1.0 \\
\hline
\end{tabular}

Table 2. Lumbar puncture

\begin{tabular}{ll}
\hline CSF investigation & Value \\
\hline Glucose, mmol/L & 1.53 \\
Protein, g/L & 1.95 \\
WBC, cells/ $\mu \mathrm{L}$ & 229 \\
Lymphocyte, \% & 92 \\
Monocyte, \% & 4 \\
Neutrophils, \% & 4 \\
RBC, cells/ $\mu \mathrm{L}$ & 18 \\
Mycobacterium tuberculosis PCR & Negative \\
Herpes simplex virus 1 and 2 PCR & Negative \\
\hline
\end{tabular}

